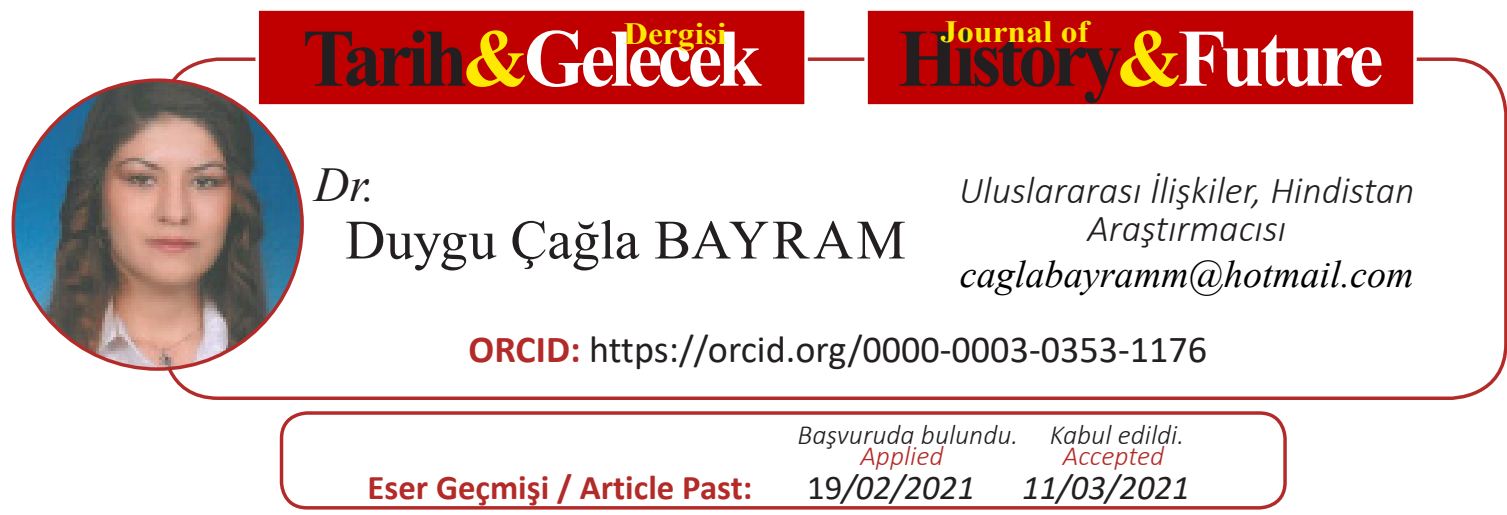

Araştırma Makalesi

DOI: http://dx.doi.org/10.21551/jhf.883091

Research Paper

Orjinal Makale / Orginal Paper

\title{
Keşmir Çatışmasının Tarihsel Kodları
} Historical Codes of the Kashmir Conflict

Öz

İngilizlerin Hint Alt Kıtası'ndan çekilme süreciyle güç boşluğunun oluşması ve dini çatışmaların başlaması üzerine kurulan Hindistan ve Pakistan devletleri arasında Keşmir'in egemenliğine ilişkin anlaşmazlık ortaya çıkmıştır. Hindistan ve Pakistan arasında Kontrol Hattı olarak adlandırılan bir sınırla bölünmüş olan Keşmir, iki ülke arasındaki en büyük gerilim kaynağıdır; iki ülkenin üç savaşına, sayısız çatışmasına ve askeri kavgalarına ve her ikisinin de nükleer silah geliştirmesine yol açmıştır. 1947 itibarıyla doğan Keşmir çatışması Hindistan ve Pakistan tarafından düşük yoğunluklu çatışmalar, ateşkes ihlalleri, sınır ötesi terörizm ve insan hakları ihlalleriyle hala devam etmekte, dolayısıyla çözüme yakın görünmemektedir. 1947'ye kadar yaşanan süreci odak alan çalışma, Keşmir çatışmasının tarihsel kodlarını analiz etmektedir. Bununla birlikte bölgedeki iki devlet arasında öngörülebilir bir zamanda çözülemeyecek bir soruna İngilizlerin neden olduğunu ve Keşmir çatışmasının hiçbir zaman gerçek anlamda tamamlanamayan bölünme sürecinin doğrudan bir ürünü olduğunu öne sürmektedir.

Anahtar Kelimeler: Keşmir, Hindistan, Pakistan

\section{Abstract}

The dispute over the sovereignty of Kashmir has emerged between the states of India and Pakistan which were established upon the emergence of power vacuum and the beginning of religious conflicts with the process of British withdrawal from the Indian Subcontinent. Divided by a border between India and Pakistan called the Line of Control ( $\mathrm{LoC})$, Kashmir is the biggest source of tension between the two countries; it has led to three wars of the two, numerous conflicts and military tussles, and both to develop nuclear weapons. The born Kashmir conflict as of 1947 is still being continuous by India and Pakistan with low intensity conflicts, ceasefire violations, cross border terrorism, and human rights violations; therefore, it seems to be no nearer to a solution. The paper focusing on the process until 1947 analyses historical codes of the Kashmir conflict. However, it argues that was the British to cause the problem between the two states in the region that could not be resolved in a predictable time, and that the Kashmir conflict was a direct product of the process of partition which was never truly completed.

Keywords: Kashmir, India, Pakistan 


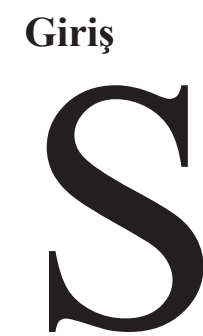

ömürgelerin tasfiyesi kaçınılmaz olduğunda Britanya İmparatorluğu Hint Alt Kıtası'nı din temelinde bölerek çekilmiştir. 1947 Hindistan Bağımsızlık Yasası ile Britanya Hindistanı Hindu çoğunluğunda Hindistan ve Müslüman çoğunluğunda Pakistan olmak üzere ikiye bölünmüştür. Bununla birlikte sayıları 500'ün üzerinde ifade edilen, Alt Kita'nın kara kütlesinin \%45'ini kaplayan ve Müslüman, Hindu ve Sih feodal hükümdarlar tarafindan yönetilen ve en önemlisi Britanya İmparatorluğu tarafından dolaylı yönetim stratejisinin uygulandığı prens devletlerin bağımsızlı̆̆ konusunda İngilizler kesin bir hüküm vermemiş, söze konu prenslikler teoride bağımsız devlet statüsünde olabileceği gibi pratikte coğrafi konum ve toplumsal çıkarlar da dikkate alınarak Müslümanların çoğunlukta olduğu bölgelerin Pakistan'a ve Müslüman olmayan çoğunluk bölgelerinin Hindistan'a katılması kararlaştırılmıştır. Bu sayede Müslüman nüfusun çoğunluğuna sahip Pakistan'a komşu devletlerin Pakistan'a ve Müslüman olmayan nüfusun çoğunluğuna sahip Hindistan'a komşu olan devletlerin Hindistan'a katılımı söz konusu olmuştur.

Ancak prensliklerin Hindistan'a ya da Pakistan'a katılımı bu kadar sorunsuz değildir. Katılım sürecinde her ne kadar üç istisna söz konusu olsa da bunlardan yöneticilerin Müslüman ve halkın çoğunluğunun Hindu olduğu Hyderabad ve Junagadh ilk etapta bağımsız olmayı istemelerine karşın bu devletlerin Hindistan'a katılımları çok sorunlu olmamıştır: İlkinin, Hindistan'ın sınırlı askeri harekatıyla; ikincisinin, referandumla katılımı gerçekleşmiştir. ${ }^{1}$ Buna karşın halkın çoğunluğunun Müslüman ve yönetici ailenin Hindu olduğu Keşmir ${ }^{2}$ ise Hindistan ve Pakistan arasında 74 y1ldır çözülemeyen ve yakın gelecekte çözülmesi zor görünen bir çatışma ${ }^{3}$ halini almıştır.

İki Ulus Teorisi temelinde aynı kökten iki siyasi varlık olarak ortaya çıkan, dolayısıyla iki kardeş olan Hindistan ile Pakistan'ın bugüne kadar ve bugün hala bir anlamda iki düşman kardeş olmasının en önemli kaynağı Keşmir'dir. Tarih boyunca kuzeybatıdan istilalara uğrayan Hindistan'ın kuzeybatı sınırını güvence altına alması bağlamında Keşmir'in önemi büyüktür. Keşmir ayrıca Hindistan için laik kimliğinin bir örneğidir; Afganistan'la fiziksel bağı söz konusudur ve Orta Asya'ya açılan tek penceredir; Jammu ve Keşmir Maharacası Hari Singh tarafından imzalanan katılım belgesine göre Hindistan'ın ayrılmaz bir parçasıdır. Pakistan açısından Keşmir, bölünme mantığının temel prensibi uyarınca, Müslüman çoğunluğu nedeniyle Pakistan'ın bir parçası olmalıdır. Ayrıca tarım ekonomisi Pakistan için ne kadar önemliyse Pakistan'ın tarım ekonomisi için Keşmir o kadar önemlidir. Keşmir'in başlıca büyük beş nehirden dördünün kaynağı (İndus, Jhelum, Chenab ve Ravi) Jammu ve Keşmir'in kuzey ve doğusundaki büyük Himalaya sıradağlarıdır

1 Hint askeri birlikleri zaten Junagadh’ı ele geçirmiştir ancak sonrasında yapılan referandum ile Hindistan'ın buradaki egemenliği meşrulaşmıştır.

2 Çalışma, Keşmir ifadesini sadece bu bölgenin küçük bir parçası olan Keşmir Vadisi’ni değil, Hindistan ve Pakistan'ın tartıştığı tüm alanı ve ayrıca bir kısaltma aracı olarak literatürde yaygın biçimde yer aldığı üzere Jammu ve Keşmir Devleti’ni ifade etmek için kullanır. Özel olarak Keşmir Vadisi’ne atıfta bulunurken Keşmir Vadisi ya da Vadi olarak ifade edilmiştir.

3 Keşmir'in kuzey sınırları, Himalayalar'ın 1ssızlığı nedeniyle net bir biçimde tanımlanmamıştır. 1950’lerde İngiliz haritalarında gösterilen en kuzeydeki sınırın güney topraklarında hak iddia eden ve Hindistan'la 1962 savaşından ve Pakistan'la 1963 tarihli devir anlaşmasından sonra bu bölgede kontrol sahibi olan Çin Hindistan'la ayrı bir anlaşmazlık içindedir. Dolayısıyla Keşmir çatışmasında üçüncü bir taraf olarak Çin yer alır ancak bu başka bir çalışma konusudur ve bu çalışma, sınırları dahilinde salt çatışmanın doğuşunu, dolayısıyla Hindistan ve Pakistan’ı odak almışı̧ır. 
ve beşinci (Satluj ve Beas) nehirle birlikte hepsi Batı Punjab'a akmaktadır. Bu nedenle Keşmir'in kontrolü suyun kontrolü demektir. Keşmir'in kontrolü ayrıca verimli toprakların kontrolü anlamına gelir.

Keşmir çatışmasının doğuşuna odaklanan çalışma tarihsel bir analiz sunarak ana hatlarıyla bölünme zamanı olan 1947'ye kadarki süreci konu edinir. Dolayısıyla Hindistan ile Pakistan özelinde gelişen çalışma son kısımda iki devletin temel Keşmir argümanlarına yer verir. Çalışmanın amacı Keşmir çatışmasını doğuran tarihsel kodları ortaya koyar ve ana argümanı çatışmanın İngilizler eliyle Alt Kıta'daki toplumsal bölünmenin ve tam anlamıyla tamamlanamayan bölünme sürecinin doğrudan bir ürünü olduğunu savunur.

\section{Keşmir'in Erken Dönem Tarihçesi}

Hindistan'ın hemen hemen tüm bölgelerinde Hindu dönemiyle ilgili tarihsel materyal yetersizdir. M.S. 12. yüzyılda yaşamış olan Keşmirli Brahmin Bilge Kalhana'nın Sanskrit dilinde kaleme aldığı ünlü Rajatarangini (Keşmir Krallarının Tarihçesi) isimli destansı derleme kitabı Keşmir tarihinin ilk yazılı kaydı niteliğindedir. Kalhana'ya göre Keşmir'in bilinen tarihi Vadi'deki monarşik hükümet sisteminin temellerini atan Gonanda Hanedanlığı'yla beraber M.Ö. 2.450'den itibaren başlamıştır. ${ }^{4}$

Maurya İmparatoru Ashoka'nın (M.Ö. 274-M.Ö. 237) M.Ö. 3. yüzyılın ortalarında Vadi’yi fethetmesiyle Keşmir tarihine yönelik yazılı kaynakların ilk referansları da vücut bulmuştur. Bunun yanı sıra erken dönem Hinduizm olarak bilinen Vedik Brahminizm de bölgede etkisini yitirmeye başlamıştır. Budist İmparator Ashoka ile Keşmir Vadisi'nde kendine yer bulan Budizm, M.S. 1. yüzyılda Kuşanların Hindistan'ın kuzeyindeki birçok bölgeyle birlikte Vadi'yi hakimiyet altına almalarının ardından daha da popüler hale gelmiştir. Öte yandan Hunlar tarafından Vadi'nin kontrolünün ele geçirilmesiyle beraber 6. yüzyıldan itibaren Budizm zayıflamış ve yerini yeniden Brahminizm'in (Hinduizm) yayılımına bırakmıştır. Ancak Hindu kralların kötü yönetimi Keşmir'de İslam'ın hızla yaygınlaşmasına neden olmuş ve 14. yüzyıldan itibaren Müslüman yönetiminin temellerini atmıştır. ${ }^{5}$

Keşmir'in 16. yüzyılın sonlarında Babür İmparatorluğu'na katılmasıyla kendi başına bir krallık olarak uzun tarihi sona ererken aynı zamanda Vadi'nin Babürler tarafindan fethi genellikle Keşmir'in modern tarihinin başlangıcı olarak kabul edilir. Vadide 166 yıl boyunca süren Babür yönetimi 18. yüzyılın ortalarında yerini Afgan yönetimine bırakmış ancak Hindulara karşı baskıcı bir tutum benimseyen Afgan yöneticileri Sihlerin Keşmir kontrolünü devralmasını kolaylaştırmıştır. ${ }^{6}$ 19. yüzyılın başlarında Punjab bölgesi merkez olmak üzere kuzey ve kuzey batı Hindistan'da küçük bir imparatorluk kuran Sih savaşçısı Ranjit Singh'in fetihlerine Keşmir'i de eklemesi bu kez Vadi'deki Müslümanları baskıcı uygulamalarla karşı kaşıya bırakmıştır. ${ }^{7}$ Sihler Keşmir'i 1839'da Ranjit Singh'in ölümüyle sona eren 27 yıllık bir süre boyunca yönetmiş ve bu tarihten itibaren Keşmir Vadisi, Jammu, Ladakh, Gilgit ve Baltistan dahil olmak üzere Jammu ve Keşmir Devleti

4 Prem Nath Bazaz, The History of Struggle for Freedom in Kashmir: Cultural and Political, from the Earliest Times to the Present Day, Kashmir Publishing Company, New Delhi, 1954, 2-3,5.

5 A.g.e. $48-50$.

6 Victoria Schofield, Kashmir in Conflict: India, Pakistan and the Unending War, I.B. Tauris, New York, 2003, 3-5.

7 Prem Nath Bazaz, The History of Struggle for Freedom in Kashmir, 118-9. 
20. yüzyılın ortalarında Hint Alt Kıtası'nın bölünme zamanına kadar Hindu Dogra Hanedanlığı eliyle Britanya İmparatorluğu’nun “dolaylı yönetimi” altında kalmıştır.

\section{Keşmir Çatışmasının Kökenleri}

Hint Alt Kıtası'ndaki prensliklerin en büyüklerinden biri $222.870 \mathrm{~km}^{2}$ yüzölçümüyle Jammu ve Keşmir Devleti'dir. Prens devletlerin navab ve maharaca/mihrace olarak adlandırılan hükümdarları kendi yönetimlerini koruma altına almak için "Britanya üstünlüğünü” kabul etmiş ve böylece Alt Kıta'nın geri kalanını doğrudan kontrol eden İngilizlerin buradaki "dolaylı yönetim” sisteminin temelini teşkil etmişlerdir.

Jammu ve Keşmir'in yönetici ailesini, Jammu bölgesinden varna (kast) sisteminin üst sınıfında yer alan ve Hindulardan oluşan etnik dil grubundaki Dogralar teşkil etmiştir. Dogra soyunun kurucusu Gulab Singh, Sih Maharaca Ranjit Singh'in hükümdarlığındaki prenslerden biridir. 1820 ve 1830'lar boyunca tüm Jammu, Ladakh ve Baltistan bölgelerine kadar kendi hakimiyetini kademeli olarak genişleten Gulab Singh, Ranjit Singh'in 1839'daki ölümünü firsata çevirerek Sih gücünü tamamen ortadan kaldırmak için İngilizlerle iş birliği yapmıştır. ${ }^{8}$ Gulab Singh'in İngilizlerle iş birliği ayrıca 1845-6 Anglo-Sih savaşlarında İngilizlere galibiyet getirmiştir. ${ }^{9}$ Galibiyet sonucu imzalanan ve Keşmir Vadisi'nin Sihlerden İngilizlere devrini konu alan 9 Mart 1846 tarihli Lahor Antlaşması aynı zamanda Gulab Singh için önemli bir kazanımdır. Nitekim 15 Mart 1846'da imzalanan Amritsar Antlaşması'yla da İngilizler 7,5 milyon rupi gibi sembolik bir bedel karşılığında Vadi'yi Gulab Singh'e devretmiştir. ${ }^{10}$

10 maddeden oluşan ve Keşmir halkının hakları, çıkarları ve geleceğinden hiç söz etmeyen ${ }^{11}$ Amritsar Antlaşması, Jammu Maharacası Gulab Singh ve soyundan gelen erkek varislerine Keşmir Vadisi ile kuzeydeki Gilgit bölgesi üzerinde daimi ve bağımsız mülkiyet ve idare hakkını veren ve aynı zamanda Jammu ve Keşmir'i Britanya Hindistanı'ndaki en büyük prens devletlerden biri olarak ortaya çıkaran oldukça önemli bir gelişmedir. Böylece 1846'da Keşmir Vadisi, Jammu, Ladakh, Gilgit ve Baltistan'1 içeren mevcut Jammu ve Keşmir Devleti kurulmuşs²* ve 100 y1l boyunca Gulab Singh ve soyundan gelenler olmak üzere Dogra seçkinleri tarafından yönetilmiştir. Dogralar, Bazaz'in ifadeleriyle

'Keşmir'in eski yöneticilerinden farklıydı çünkü kendileri de başka bir gücün, İngilizlerin vasallarıydı. Onlar, Dograların efendi konumuna yükseltildiği ve Dogra olmayan tüm topluluklar ile sınıfların alt kademede bırakıldığı devlette bir tür Dogra emperyalizmi kurdular. Vadi halkı böylece kendisi de İngiliz süper-emperyalizminin bir tebaası olarak işlev gören Dograların emperyalizmine maruz birakıld1. Ancak Dogra emperyalizmi sefalet, esaret, fiziksel ve zihinsel bozulmadan başka bir şey getirmemiş olsa da diğer emperyalizm bazı nimetlerle geldi. Vadi,

8 Sumantra Bose, Kashmir: Roots of Conflict, Paths to Peace, Harvard University Press, Cambridge, 2003, 15.

9 Victoria Schofield, Kashmir in Conflict, 6.

10 Alastair Lamb, Kashmir: A Disputed Legacy 1846-1990, Roxford Books, Hertingfordbury, $1991,8$.

11 Naghma Mangrio, "A Historical and Political Perspective of Kashmir Issue”, The Dialogue, Cilt 7, Say1 $3,2012,258$.

12 * Jammu ve Keşmir gerçekte Güney Asya'daki İngiliz sınırını korumak ve bölgedeki Rus genişlemesine karşı koymak için İngiliz Korumacılığı altında bir Sınır Devleti olarak kurulmuştur. Suddepto Adhikari ve Mukul Kamle, "The Kashmir: An Unresolved Dispute Between India and Pakistan", Geopolitics Quarterly, Cilt 6, Say1 4, 2010, 65. 
İngiliz hükümdarlığı altına girerek insanlarda bağımsızlık ve özgürlük gibi doğuştan kazanılan hakları talep etme farkındalığı uyandıran Batı fikirlerinin ve modern medeniyetin etkisine sahip olmaya başladı."

Bazaz'ın söylemiyle “modernizm, Dogra yönetimi sirasinda Vadi'ye geldi ancak Dograların Keşmirlileri görüşste, eğitimde ve kültürde modern yapmak istediğinden değil, [modernizm] onlara karşın [Vadi'ye geldi]". ${ }^{14}$ Öte yandan Dogra yönetimindeki Müslüman topluluğun durumunu Copland, "Güneydeki ya da Jammu bölgesindeki nüfusun \%53'ünü ve daha kalabalık olan kuzeyde ya da Keşmir bölgesinde \%93'ünü oluşturmalarına karşın zenginlik veya nüfuzdan yoksun bir topluluk" ${ }^{5}$ olarak özetler. Bazaz ise bu durumu şöyle ifade eder: "Müslümanlar Jammu ve Keşmir Devleti'nin genelinde nüfusun büyük çoğunluğunu (yaklaşık \%78) ve salt Keşmir Vadisi'nde \%94'ünü oluştururken hayatın her alanında Keşmir Hindularından daha haksız muamele görmüştür". ${ }^{16}$

Dograların kontrolü altında çoğunluğu Müslüman olmak üzere Keşmirliler kendi topraklarında yabancılaşmış ve bu durum eğitimli Keşmirlilerin önderlik ettiği "Keşmirliler için Keşmir" olarak bilinen toplumsal hareketlenmenin doğmasına yol açmıştır. Jammu ve Keşmir'in ilk siyasi partisi olan "Tüm Jammu ve Keşmir Müslüman Konferansı" sosyal ve politik değişim adına oluşan söze konu hareketi yönetmek için Vadi'den "Keşmir Aslanı" olarak ünlenen Şeyh Mohammad Abdullah ve Jammu bölgesinden Chaudhary Ghulam Abbas liderliğinde Ekim 1932'de kurulmuştur. Parti ismi 1939 'da devlet siyasetini laik çizgide yeniden yönlendirmek ve daha da önemlisi özgürlüğüne inanan Keşmirli Hindu ve Sihleri harekete dahil etmek için "Jammu ve Keşmir Ulusal Konferansı" olarak güncellenmiştir. Buna karşın Ulusal Konferans'ın Müslüman yönelimi bir dereceye kadar kaçınılmaz olmuştur çünkü Müslüman çoğunluğa sahip devlette vücut bulan toplumsal hareket yozlaşmış, baskıcı ve Hindu egemen hiyerarşisine yönelik gelişmiştir. ${ }^{17}$

1942'de Quit Kashmir (Keşmir'i Terk Et) hareketini başlatan ve 1944'te ulusal ekonomik plan ve anayasaya ilişkin Naya Kashmir (Yeni Keşmir) adlı manifestosunu ilan eden Şeyh Mohammad Abdullah'ın en büyük önceliği Keşmir halkını Dogra boyunduruğundan kurtarmak olmuştur. ${ }^{18}$ Keşmir halkının kendi kaderini tayin etme mücadelesini destekleyen ve Keşmir'deki demokratik unsurların sağlamlaştırılmasında önemli bir rol oynayan Abdullah, laik ve seküler bir çizgide din ve parti üstü bir siyaset izleyerek Keşmir milliyetçiliğinin (Keşmiriyat/Keşmirlilik) güçlü bir savunucusu olmuştur. ${ }^{19}$ Bunun yanı sıra Şeyh Abdullah'ın kişisel seçimi belirsiz kalmıştır. İki Ulus Teorisi'ne inanmadığı için bölünmeye karşı çıkmış ancak Hindistan'a da katılmak istememiştir çünkü Pakistan'ın bu yöndeki bir seçimi kabul etmeyeceğini ve dolayısıyla Keşmir'in bir savaş alanı olacağını düşünmüştür. Keşmir'in bağımsız bir devlet olması konusunda ise büyük güçlerle

13 Prem Nath Bazaz, The History of Struggle for Freedom in Kashmir, 127.

14 A.g.e. 128.

15 Ian Copland, "Islam and Political Mobilization in Kashmir, 1931-34", Pacific Affairs, Cilt 54, Say1 2 , 1981, 233.

16 Prem Nath Bazaz, The History of Struggle for Freedom in Kashmir, 143.

17 Sumantra Bose, Kashmir: Roots of Conflict, Paths to Peace, 20,24.

18 A.g.e. 25-7; Prem Nath Bazaz, The History of Struggle for Freedom in Kashmir, 217-21.

19 Nyla Ali Khan, Sheikh Mohammad Abdullah's Reflections on Kashmir, Palgrave Macmillan, New York, 2018; Ramachandra Guha, “Opening a Window in Kashmir", World Policy Journal, Cilt 21, Say1 3, 2004, 79-94. 
çevrili küçük bir devletin bağımsız kalmasının imkansız olduğuna inanmıştır. ${ }^{20}$

\section{Hint Alt Kıtası’nın Bölünmesi ve Keşmir Çatışmasının Doğuşu}

İngilizlerin alt kıtadan çekilme kuralları Britanya Hindistanı'nın son genel valisi olan Louis Mountbatten tarafından 3 Haziran 1947' de yayınlamıştır. Mountbatten Planı olarak bilinen kurallar uyarınca Hint Alt Kıtası 15 Ağustos 1947'de bağımsız olmuştur. Ancak 1947 Hindistan Bağımsızlık Yasası Britanya Hindistanı'nı Hindistan ve Pakistan olmak üzere iki bağımsız ülkeye bölmüştür. Bununla beraber Punjab ile Bengal bölgeleri de Doğu ve Batı olmak üzere ikiye bölünmüştür. Ayrıca Bağımsızlık Yasası'nın hükümlerince Britanya Hindistanı'nın dolaylı yönetiminde bulunan diğer prens devletlerin yöneticilerine Hindistan'a veya Pakistan'a katılma seçeneği verilmekle birlikte bu devletler kendi haline bırakılmış, diğer deyişle bağımsız kalmışlardır. ${ }^{21}$ Bu devletlerin Hindistan veya Pakistan'a katılmaları durumunda Mountbatten Planı'nda bazı yol gösterici ilkeler önerilmiş ve yöneticilere devletlerinin coğrafi konumunu ve halkın isteklerini göz önünde bulundurarak katılım kararını vermeleri tavsiye edilmiştir. ${ }^{22}$ Alt Kıta'daki bölünme ve coğrafi sınırlar din temelinde çizilmiş; Sind, Belucistan ve Kuzey Batı Sınır bölgelerinin yanı sıra Punjab ve Bengal'in Müslüman çoğunluklu toprakları Pakistan'da, Britanya Hindistanı'nın geri kalan bölümleri ise Hindistan'da kalmıştır. ${ }^{23}$

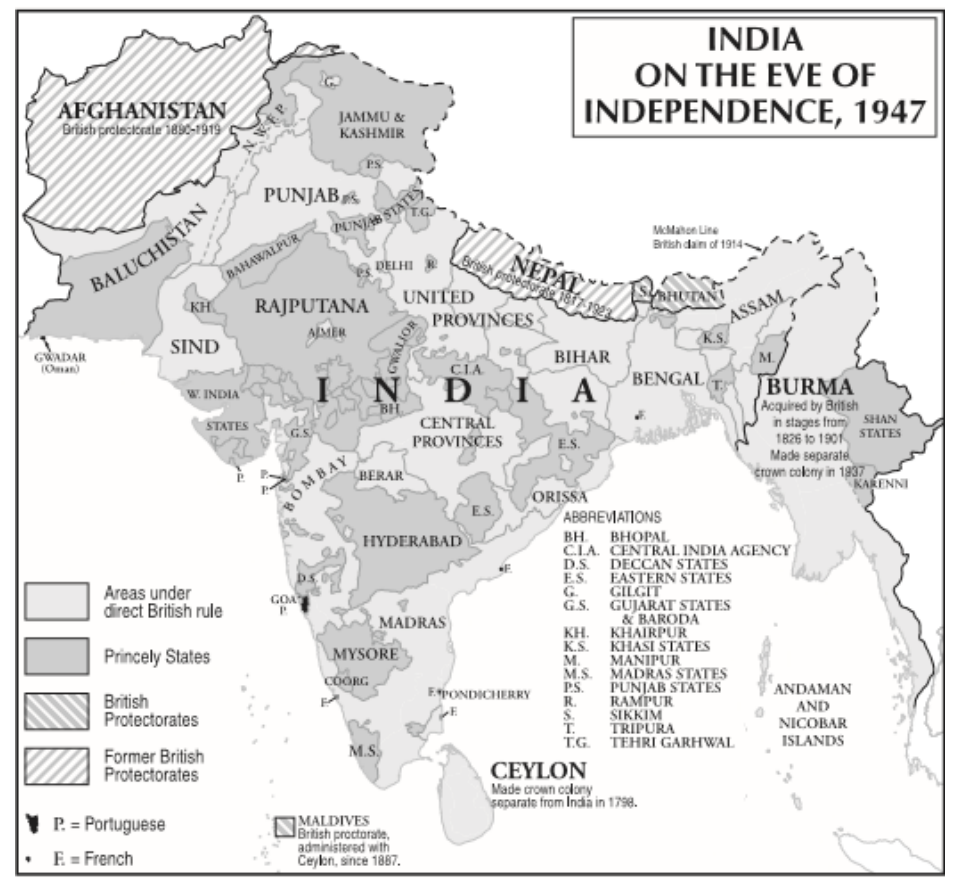

Harita 1: Bölünme Öncesi Hindistan ${ }^{24}$

Alt Kıta’ya yayılmış, farklı coğrafi büyüklükte ve çoğu karayla çevrili prens devletler teknik olarak tamamen bağımsız hale gelirken bağımsızlık, Hindistan veya Pakistan tarafından çevrelenen

20 Navnita Chadha Behera, Demystifying Kashmir, Brookings Institution Press, Washington DC, 2006, 24.

21 Y. Hikmet Bayur, Hindistan Tarihi III. Cilt, Türk Tarih Kurumu Basımevi, Ankara, 1987, 649-57.

22 Naghma Mangrio, "A Historical and Political Perspective of Kashmir Issue”, 261.

23 Alastair Lamb, Kashmir: A Disputed Legacy 1846-1990, 104; Suddepto Adhikari ve Mukul Kamle, "The Kashmir: An Unresolved Dispute Between India and Pakistan", 66.

24 Navnita Chadha Behera, Demystifying Kashmir, 5. 
ve genellikle uluslararası arenada kendilerini koruyamayacak kadar küçük olan devletlerin büyük çoğunluğu için ne uygulanabilecek ne de istenebilecek bir durumdur. ${ }^{25}$ Dolayısıyla her ne kadar teoride bağımsızlık seçenekleri bulunsa da pratikte prens devletlerin Hindistan'a ya da Pakistan'a katılmalarının dışında üçüncü bir alternatifi olmamıştır. ${ }^{26}$

Buna karşın Jammu ve Keşmir Devleti ilk etapta bağımsızlık talep etmiştir. Bunun nedenleri kısaca şöyle sıralanabilir: Öncelikle Keşmir çok büyük bir prens devletidir; İngiltere'den daha büyük ve neredeyse Birleşik Krallık büyüklügündedir. İkincisi, Keşmir hem Hindistan hem de Pakistan'la sınırdaştır. Her ikisi de kendisini çevrelediği için Keşmir doğrudan bir seçim yapamamıştır. Keşmir'in ayrıca Çin ve Afganistan'la da sınırı bulunmaktadır ve böylesine büyük bir jeopolitik önem onun bağımsızlığı istemek için coğrafi potansiyele sahip olduğunu gösterir. Öte yandan Keşmir, Hindu monarşisine ve ağırlıklı olarak Müslüman nüfusa sahiptir. Bu durum din temelinde bölünmenin yaşandığı sırada Maharaca'nın tarafsız bir tutum sergilemesine yol açmıştır. ${ }^{27}$

Mangrio’ya göre Pakistan'ın kurulması Hindu Dogra yönetiminin acımasızlığından kurtularak kendi kaderlerini yazmaya çok yakın olduklarını düşünen Keşmirliler için mutluluk kaynağı olsa da ${ }^{28}$ Jammu ve Keşmir Devleti için süreç çok farklı ilerlemiştir. Yönetimde bulunan Gulab Singh'in son varisi Maharaca Hari Singh bağımsızlık çabasıyla katılım belgesini imzalamayarak yerine 1947 Hindistan Bağımsızlık Yasası'nın öngördüğü üzere Hindistan ve Pakistan'a standstill (mevcut durumu koruma) anlaşmaları önermiştir. Adından da anlaşılacağı üzere bu anlaşma sayesinde Britanya Hindistanı ile prens devletler arasında şekillenmiş olan ilişki Alt Kıta'nın yeni konjonktüründe de korunacaktır. Keşmir, altyapı (dış dünyaya karayolu ve demiryolu bağlantıları, telgraf hatları ile posta yolları), ticaret ve savunma için Britanya Hindistanı'na bağımlıdır ${ }^{29}$ ve standstill anlaşmalarıyla Maharaca söze konu temel hizmetleri sürdürmek ve bağımsızlı̆̆ını sağlamlaştırmak istemiştir.

Pakistan anlaşmayı kabul ederken Hindistan ise prens devletlerin katılım belgesi imzalayıncaya kadar onlarla standstill anlaşmaları yapmamaya yönelik bir politika izlemiştir. ${ }^{30}$ Bu sıralarda Jammu ve Keşmir Devleti'nde özerk bir prenslik olan ve yerel hükümdarın Dogra yönetimi tarafından görevden alınana kadar kendi racası tarafından yönetilen ${ }^{31}$ Poonch bölgesindeki Müslümanlar Pakistan'a katılım taleplerinde bulunmuş ve Pakistan'dan Pathan (Peştun) aşiretleri tarafından da destek görmeye başlayan talepler zamanla isyan hareketine dönüşmüştür. Bunun üzerine Maharaca Hindistan'dan askeri yardım istemiş ve Hindistan ise katılım belgesinin imzalanmasını şart koşmuştur. ${ }^{32}$ Bunun dayanağı olarak katılımdan önce askeri müdahalenin yasal

25 Michael R. McCarthy, A Subject of Dispute: A Legal Analysis of the Claims of India and Pakistan to Kashmir, Durham theses, Durham University, 2002, 1.

26 Suddepto Adhikari ve Mukul Kamle, "The Kashmir: An Unresolved Dispute Between India and Pakistan", 67.

27 Michael R. McCarthy, A Subject of Dispute: A Legal Analysis of the Claims of India and Pakistan to Kashmir, 2.

28 Naghma Mangrio, "A Historical and Political Perspective of Kashmir Issue”, 260.

29 Sheikh Mohammad Abdullah, "India, Pakistan and Kashmir", Foreign Affairs, Cilt 43, Say1 3, 1965, 528.

30 Michael R. McCarthy, A Subject of Dispute: A Legal Analysis of the Claims of India and Pakistan to Kashmir, 16. Hindistan'ın bu politikasında bir istisnası vardır: Hyderabad katılım belgesi imzalamadan onunla standstill anlaşması imzalamıştır.

31 Sumantra Bose, Kashmir: Roots of Conflict, Paths to Peace, 32.

32 Michael R. McCarthy, A Subject of Dispute: A Legal Analysis of the Claims of India and Pakistan to 
açıdan Hindistan'ın tarafsız bir bölgeyi işgal etmesi anlamına geleceğinden Britanya Hindistanı Genel Valisi Mountbatten'ın öncelikle Jammu ve Keşmir'in Hindistan'a katılımını güvence altına almadan asker göndermemelerini tavsiye etmesi gösterilmiştir. Ancak Mountbatten Maharaca'nın katılım kabulünü bir anlamda şartlı onaylamış, yasa ve düzen yeniden sağlandıktan sonra katılımın "halka danışılarak" onaylanması gerektiğini ifade etmiştir. ${ }^{33}$

Hari Singh'in tartışmalı katılım belgesini 26 Ekim 1947'de imzalayarak Hindistan'a katılmayı kabul etmesi günümüze dek çözülmeden gelen Keşmir çatışmasını doğurmuştur. Böylelikle Hint kuvvetleri isyancılarla başa çıkmak için Keşmir'e girmiş ve sonucunda Pakistan sınırından biraz uzakta kuzey-güney yönünde uzanan ve ardından Keşmir' in batı ve kuzeybatı bölgeleri isyancıların kontrolü altında olacak şekilde doğuya kıvrılan bir hat belirmiştir. Hattın batısındaki Azad (Özgür) Keşmir ve kuzeyindeki Gilgit ve Baltistan (Kuzey Bölgeleri) toprakları Pakistan, geri kalanı (Keşmir Vadisi ve Jammu ile Ladakh topraklarının büyük çoğunluğu) Hindistan sınırlarında yer almıştır. ${ }^{34}$ De facto olarak oluşan bu sınır, 1972'de imzalanan Simla Anlaşmasıyla "Kontrol Hattı" (Line of Control-LoC) olarak yeniden adlandırılıncaya kadar "Ateşkes Hattı" (Ceasefire LineCFL) olarak bilinir. Kanla çizilen bu fiili sınır bölgesel olarak açıkça Hindistan'ın lehine olduğu için Keşmir çatışmasında Hindistan Güney Asya'nın statüko gücü olurken Pakistan revizyonist güç olarak görülmüştür. ${ }^{35}$

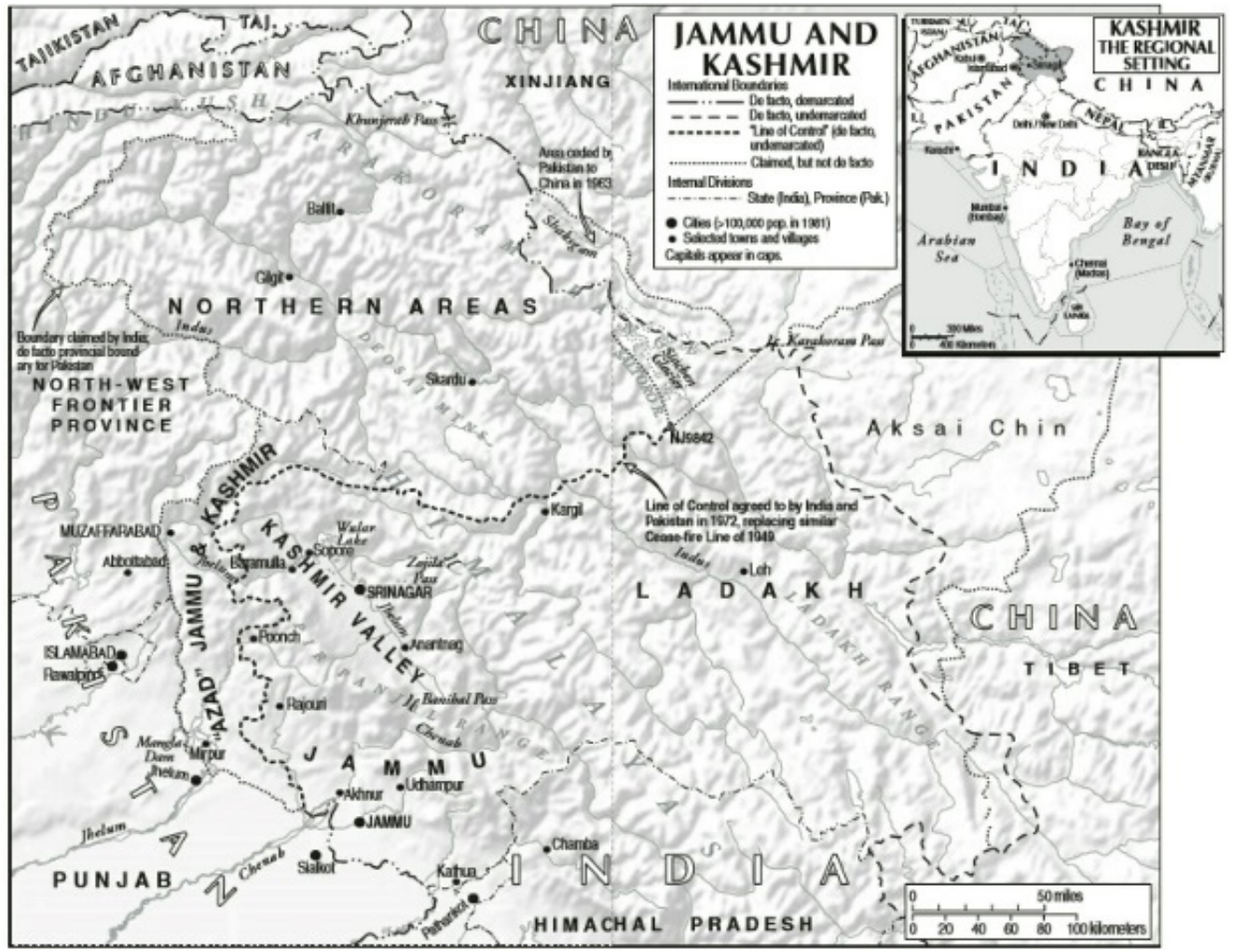

Harita 2: Keşmir $^{36}$

Kashmir, 20.

33 Sumantra Bose, Kashmir: Roots of Conflict, Paths to Peace, 35-6.

34 Alastair Lamb, Kashmir: A Disputed Legacy 1846-1990, 342.

35 Sumantra Bose, Kashmir: Roots of Conflict, Paths to Peace, 42.

36 A.g.e. 
2 Kasım 1947'de Hindistan Kurucu Başbakanı Jawaharlal Nehru, Jammu ve Keşmir halkının nihayetinde Hindistan'ı mı yoksa Pakistan'ı mı tercih ettiğini belirlemek için hükümetinin yalnızca Keşmir halkına değil, dünyaya Birleşmiş Milletler gibi uluslararası gözetim altında referandum düzenleme sözünü verdiğini açıklamış ${ }^{37}$ ve 1950 'lerin ortalarına kadar sözünün arkasında olduğunu defalarca yinelemiştir. Bunula beraber sınırdaki Pakistan destekli saldırganlı̆ga ilişkin Hindistan'ın şikayeti üzerine Birleşmiş Milletler Güvenlik Konseyi (BMGK) barış ve düzenin yeniden tesis edilebilmesi ve akabinde bir plebisitin yapılabilmesi adına Keşmir'de arabuluculuk rolü oynaması için Ocak 1948'de "Birleşmiş Milletler Hindistan ve Pakistan Komisyonu"nu (UNCIP) kurmuş̧tur. Plebisitin hiçbir zaman yapılmaması Pakistan ve Pakistan yanlıları tarafindan olduğu kadar Keşmir'deki bağımsızlık yanlıları tarafından da Hindistan'ın haksızlığının kanıtı olarak görülürken Hindistan'ın argümanı ise Pakistan güçleri kontrolleri altındaki Keşmir alanlarını terk etmediği için Birleşmiş Milletler tarafından plebisitin ilk şartının yerine getirilmemiş olması ve dolayısıyla suçun Pakistan'da olmasıdır. ${ }^{38}$ Bu noktada beliren bir başka görüş ise BMGK Kararı'nın ardından Pakistan'ın Keşmir topraklarını terk ettiğinde kendi desteğiyle Müslüman aşiret kontrolü altında olan Kuzey Bölgeleri'nin yanı sıra Azad Keşmir'in Hindistan tarafından ele geçirilmesi ve böyle bir durum karşısında uluslararası toplumun ve hatta BMGK'nın Hindistan'ı buralardan çekilmeye zorlamasının güç olmasıdır çünkü katılım belgesine ilişkin 1947 Hindistan Bağımsızlık Yasası'nda yer alan hükümler uyarınca Keşmir' in katılımıyla ilgili hukuki boyutlar Hindistan'ın lehinedir. ${ }^{39}$

\section{Hindistan ve Pakistan'ın Keşmir Argümanları}

Hindistan iddiasını Jammu ve Keşmir Maharacası'nın Hindistan'a katılımına dayandırır. Pakistan ise bu katılımın geçerliliğini reddeder. Keşmir'de patlak veren isyanların gölgesinde Maharaca'nın Keşmir'in büyük bir kısmının kontrolünü kaybettiği, halktan yeterli desteği bulamadığı ve artan kaosla baş edemediğinden dolayı Keşmir'den ayrılması ve bu pozisyonda Hindistan'la bir katılım anlaşması imzalaması söze konu katılımın geçerliliğini ve etikliğini sorgulatmıştır. ${ }^{40}$ Hindistan ordusunun Keşmir'in Hindistan'a katılımını zorladığını iddia eden Pakistan için böyle bir zorlamanın yokluğunda Keşmir'in standstill anlaşması yaptığı Pakistan'a katılımı öngörülmüş̧ür. ${ }^{41} \mathrm{Bu}$ noktada Maharaca'nın Hindistan'a katılımının gönüllü olmadığı, olağanüstü bir politik atmosferde Maharaca'ya dayatıldığı yönünde bir görüş bulunur. Ancak 1947 Hindistan Bağımsızlık Yasası'nda yer alan hükümler çerçevesinde gerçekleşen katılım hukuken doğru, etik olarak doğru olmasa da yasal olanın her zaman etiğe göre öncelik taşıdığı da doğrudur. ${ }^{42}$

Hindistan'ın argümanı Maharaca'nın Hindistan'a isteyerek katıldığıdır. Ancak burada katılım belgesini imzalamanın zamanlaması sorgulanır. Başka söyleyişle Hint birliklerinin katılım belgesini imzalamadan önce gelip gelmediği ve dolayısıyla Hindistan'ın Jammu ve Keşmir'in katılımını elde etmek için güç kullanıp kullanmadığına yönelik soru işaretleri bulunur. Katılımın

37 Navnita Chadha Behera, Demystifying Kashmir, 31.

38 Sumantra Bose, Kashmir: Roots of Conflict, Paths to Peace, 38-42.

39 Suddepto Adhikari ve Mukul Kamle, "The Kashmir: An Unresolved Dispute Between India and Pakistan", 81-2.

40 Victoria Schofield, Kashmir in Conflict, 71.

41 Michael R. McCarthy, A Subject of Dispute: A Legal Analysis of the Claims of India and Pakistan to Kashmir, 20-1.

42 Suddepto Adhikari ve Mukul Kamle, "The Kashmir: An Unresolved Dispute Between India and Pakistan", 78. 
her ne kadar hukuken şüpheli koşullar altında gerçekleştirildiği argümanı daha güçlü olsa da teknik açıdan bağımsız Keşmir devletinin başı olarak Maharaca'nın başlangıçta Hindistan'dan askeri yardım talep eden kişi olması bu tür iddiaların önüne set çekmiştir. ${ }^{43}$

Pakistan'ın Keşmir'i ablukaya alarak standstill anlaşmasını ihlal ettiği iddiasına gelince, Pakistan'ın Keşmir'i kendisine katılmaya zorlamak için ablukaya aldığı tezinin doğruluğunu mevcut kayıtlara göre belirlemek zor olsa da Hindistan açısından böyle bir emsalin vücuda gelmesi söze konu ihlal savını bulanıklaştııı. Nitekim bir standstill anlaşmasının mevcutluğuna karşın Hindistan'ın Hyderabad'ın katılımıyla ilgili davranışı bağımsız kalmak isteyen prens devletlerin stratejik olarak savunulamaz bir konumda olduğunu göstermekle beraber, Hyderabad'ın Hindistan'a katılımı gerçekleşmiş olsa da nihayetinde aynı durum Pakistan ile Keşmir için söz konusu olmamıştır. Bir diğer yönden Pakistan'la var olan standstill anlaşmasının, tarafı olan devletin Hindistan'a katılımını engelleyebileceği görüşüne gelince, iki taraf arasında vuku bulan bir standstill anlaşması üçüncü tarafı bağlamayacağından anlaşma taraflarından birinin üçüncü bir tarafa katılım sağlamasına engel teşkil etmemiştir. Nitekim standstill anlaşması güç devri sırasında düzenin bozulmasını önlemek için mevcut ilişkilerin devamına yönelik bir mekanizma işlevi görmüştür. Dolayısıyla yasal olarak prens devletlerin Hindistan'a veya Pakistan'a katılma hakkı saklı kalmıştır. ${ }^{44}$

Öte yandan Keşmir ile Pakistan arasındaki yakın bağlantılar Pakistan'ın Keşmir iddiasının temelinde yatan argümandır. Buradan hareketle Pakistan bölünmenin temel mantığının aynı zamanda katılıma rehberlik etmesi gerektiğini savunmuş ve bu bağlamda Batı Punjab'daki Müslüman bölgesinin coğrafi olarak bitişiğinde yer alan Müslüman bölgelerin Pakistan'a dahil edilmesi gerektiğini öne sürmüştür. Başka anlatımla Pakistan'ın bakış açısıyla Keşmir Pakistan'a aittir çünkü Keşmir Pakistan'ın havzasında bulunmaktadır. ${ }^{45}$ Nitekim Keşmir'in Pakistan'la dini ve kültürel bağları bulunur. Güç devri sırasında Müslümanlar tüm nüfusun yaklaşı \%78'ini ve Vadi özelinde yaklaşık \%93'ünü oluşturmuştur. ${ }^{46}$ Diğer bir ifadeyle 1941 tarihli İngiliz nüfus sayımına göre ortalama 4 milyon Keşmir nüfusunun 3 milyon 100 bini Müslüman (\%77'si), 800 bini Hindu (\%20'si), 65 bini Sih, 40 bini Budist ve 4 bini diğerlerinden oluşmaktadır. ${ }^{47}$ Ayrıca Keşmir coğrafi olarak Pakistan'a bitişiktir. Pakistan'dan geçen ana nehirler (İndus Nehri'nin kolları) Keşmir'de doğar ve Hindistan Keşmir'den dağlarla ayrılır. Dıı̧ dünyaya giden tek yol Jhelum Vadisi ile Pakistan'dan ve Keşmir'e giden tek demiryolu hattı Pakistan'daki Sialkot'tan geçmiş, posta ve telgraf hizmetleri Pakistan'a giden yollardan sağlanmıştır. Neredeyse tüm Keşmir ticareti Pakistan üzerinden gerçekleşmiştir. ${ }^{48}$ Kısacası Pakistan Jammu ve Keşmir gibi Müslüman çoğunluklu bir devletin Hindistan'a dahil edilmesiyle iki ulus teorisinin ve dolayısıyla bölünme mantığının tanınmadığını iddia ederken Hindistan Keşmir'in katılımının kendi kuruluş temeli olan seküler

43 Michael R. McCarthy, A Subject of Dispute: A Legal Analysis of the Claims of India and Pakistan to Kashmir, 21,5-7; Victoria Schofield, Kashmir in Conflict, 58.

44 Michael R. McCarthy, A Subject of Dispute: A Legal Analysis of the Claims of India and Pakistan to Kashmir, 17-9.

45 A.g.e. 13.

46 Naghma Mangrio, "A Historical and Political Perspective of Kashmir Issue", 262.

47 Prem Nath Bazaz, The History of Struggle for Freedom in Kashmir, 536; Sumantra Bose, Kashmir: Roots of Conflict, Paths to Peace, 16.

48 Michael R. McCarthy, A Subject of Dispute: A Legal Analysis of the Claims of India and Pakistan to Kashmir, 13-4. 
ulusçuluk teorisini geçerli kıldığında 1 srar eder. ${ }^{49}$

\section{Sonuç}

Keşmir çatışmasının geleceği belirsizliğini korumaktadır. Hindistan ile Pakistan ilişkilerini 1947'den bu yana altüst eden sorunun görünürde net bir çözümü yoktur ve herhangi bir öngörüde bulunmak güçtür. Ancak yine de çatışmanın niteliği ortaya konabilir ve birtakım öneriler sunulabilir.

Özü itibarıyla üç boyutlu bir egemenlik anlaşmazlığı olan Keşmir çatışması ideolojik değil, politik bir sonuçtur. Hint Alt Kıtası'ndaki bölünme mantığı Keşmir'e uygulanırsa, Keşmir'in Pakistan'a dahil edilmesi büyük bir olasılık gibi görünür. Ancak İngilizlerin çekilme koşullarına göre teoride bağımsız kalan Keşmir'in pratikte Hindistan'a katılımı söz konusu olmuştur. Sorunun kaynağı da burada başlar. Keşmir çatışması Britanya Hindistanı'nın Hindistan ile Pakistan'a bölünmesinin politik ve coğrafi ifadesi olan İki Ulus Teorisi nedeniyle Hint Ulusu'nun uğradığı toplumsal bölünmenin bir ürünüdür. Diğer deyişle söze konu bölünmenin hiçbir zaman tamamlanamamasından kaynaklanır. Bir başka anlatımla İngilizlerin çekilme sürecinde söz konusu olan gri kalmış alanlar ya da konular net bir çözümü olmayan Keşmir sorununu yaratmıştır.

Britanya Hindistanı’nın bölünme sürecine ilişkin incelemeler Keşmir’in bağımsız kalmak yerine Hindistan ya da Pakistan'a katılmasının kaçınılmaz olduğunu gösterir. Bölünme planlarında yer alan belirsizlik ya da prens devletler konusunda ucu açık bırakılan ve çok net çizilmeyen koşullar hem Hindistan'ın hem de Pakistan'ın Keşmir'i kendi bölgelerine dahil etmek için adımlar atmasına neden olmuş ve ne İngiliz bölme planı ne savaş ne de BM'nin devreye girmesi Keşmir sorununa kalıcı bir çözüm sunmuştur. Tüm bunlar Hindistan ile Pakistan'ın uzlaşmaz doğasını vurgular ve bu nedenle Keşmir sorununa net bir çözüm bulmak ya da net bir öngörüde bulunmak neredeyse imkansızdır. Ayrıca her ne kadar BM'nin konuya dahil olması anlaşmazlığı uluslararasılaştırmış olsa da Pakistan'ın Keşmir anlaşmazlığına dünya toplumunun katılımını istemesine karşın Hindistan tavrının bu noktada çok hassas ve net olması ve Keşmir'i kesinlikle kendi iç meselesi olarak görmesi de çözüm arayışlarına ket vurmaktadır.

Bugün belirlenen sınırlar her ne kadar kanla çizilmiş ve ihtilaflı olsa da BM'nin de sabitlendiği plebisit konseptini 1947 öncesi veya 1846 Keşmir'ine uygulamak da neredeyse imkansız ve anlamsız görünmektedir. Hindistan'ın kontrol edemediği ve Maharaca’ya karşı halk ayaklanmalarına sahne olan eski prens devletinin iki ana bölgesi Azad Keşmir ile Kuzey Bölgeleri’nde Hindistan hiçbir zaman egemenlik kazanamamıştır ve dolayısıyla Pakistan'ın oradaki varlığının saldırganlık olarak kabul edilmesi ve Pakistan kontrolünün yok sayılması ya da geri alınması çok güçtür. Ayrıca BM müdahalesi aynı zamanda Azad hükümetinin meşruiyetini ve Pakistan’ın Kuzey Bölgeleri üzerindeki kontrolünü tanımıştır.

Öte yandan konunun BM gözetiminde çözülmesi veya topyekun halk oylamasına gidilmesi mutlaka Pakistan'ın kazanımı olacağı anlamına gelmemektedir. Halkın çoğunluğunun Hindu olduğu Jammu ya da çoğunluğu Budist toplumdan oluşan Ladakh büyük olasılıkla Hindistan' da kalmayı tercih edecektir. Keşmir'in tüm toprakları gerçekten tartışmalı değildir ve halk oylaması muhtemelen Jammu, Ladakh, Azad Keşmir ve Kuzey Bölgeleri’nde gereksiz olur. Gerçek çatışmanın yaşandığı bölge Keşmir Vadisi gibi görünmektedir. Bu nedenle Keşmir'in de bir şekilde bölünme yaşayacağı ya da mevcut bölünmenin gerekliliği açıktır. 
Ne 1947 öncesi Jammu ve Keşmir Devleti’nin sınırlarına geri dönmek ve bir bütün olarak bu bölgenin ne bağımsız olmasını ve bu bölgeden ne Hindistan'ın ne de Pakistan'ın tamamen vazgeçmesini beklemek anlamlı bir yol haritası gibi durur. Ancak Keşmir Vadisi özelinde halkın görüşlerine danışılması Keşmir çatışmasının çözümü için büyük bir adım olabilir. Her şeyden önce anlaşmazlığa yönelik ilk adım iki tarafın diyalog mekanizmaları kurup, aralarında güven inşa etmesi olmalıdır. Nitekim çözüm her ikisinin çok daha yararına olur ki bu sayede kıt kaynaklarını daha yapıcı amaçlara ayırabilirler. Güney Asya jeopolitiğinin odak noktası olan Keşmir sorununun çözümü aynı zamanda bölgeye barışı getirecektir.

\section{Kaynakça}

Abdullah, Sheikh Mohammad, "India, Pakistan and Kashmir", Foreign Affairs, Cilt 43, Say1 $3,1965,528-35$.

Adhikari, Suddepto ve Mukul Kamle, "The Kashmir: An Unresolved Dispute Between India and Pakistan”, Geopolitics Quarterly, Cilt 6, Say1 4, 2010, 58-107.

Bayur, Y. Hikmet, Hindistan Tarihi III. Cilt, Türk Tarih Kurumu Basımevi, Ankara, 1987.

Bazaz, Prem Nath, The History of Struggle for Freedom in Kashmir: Cultural and Political, from the Earliest Times to the Present Day, Kashmir Publishing Company, New Delhi, 1954.

Behera, Navnita Chadha, Demystifying Kashmir, Brookings Institution Press, Washington DC, 2006.

Bose, Sumantra, Kashmir: Roots of Conflict, Paths to Peace, Harvard University Press, Cambridge, 2003.

Copland, Ian, "Islam and Political Mobilization in Kashmir, 1931-34", Pacific Affairs, Cilt 54, Say1 2, 1981, 228-59.

Guha, Ramachandra, "Opening a Window in Kashmir”, World Policy Journal, Cilt 21, Say1 3, 2004, 79-94.

Khan, Nyla Ali, Sheikh Mohammad Abdullah's Reflections on Kashmir, Palgrave Macmillan, New York, 2018.

Lamb, Alastair, Kashmir: A Disputed Legacy, 1846-1990, Roxford Books, Hertingfordbury, 1991.

Mangrio, Naghma, "A Historical and Political Perspective of Kashmir Issue", The Dialogue, Cilt 7, Say1 3, 2012, 255-264.

McCarthy, Michael R., A Subject of Dispute: A Legal Analysis of the Claims of India and Pakistan to Kashmir, Durham theses, Durham University, 2002.

Schofield, Victoria, Kashmir in Conflict: India, Pakistan and the Unending War, I.B. Tauris, New York, 2003. 